\title{
Surgery for postinfarction ventricular tachycardia in the pre-implantable cardioverter defibrillator era: early and long term outcomes in 100 consecutive patients
}

\author{
J P Bourke, R W F Campbell, J M McComb, S S Furniss, J C Doig, C J Hilton
}

\begin{abstract}
Objective-To report outcome following surgery for postinfarction ventricular tachycardia undertaken in patients before the use of implantable defibrillators.

Design-A retrospective review, with uniform patient selection criteria and surgical and mapping strategy throughout. Complete follow up. Long term death notification by OPCS (Office of Population Censuses and Statistics) registration. Setting-Tertiary referral centre for arrhythmia management.

Patients-100 consecutive postinfarction patients who underwent map guided endocardial resection at this hospital in the period 1981-91 for drug refractory ventricular tachyarrhythmias.

Results-Emergency surgery was required for intractable arrhythmias in $\mathbf{2 8}$ patients, and 32 had surgery within eight weeks of infarction ("early"). Surgery comprised endocardial resections in all, aneurysmectomy in 57, cryoablations in 26, and antiarrhythmic ventriculotomies in 11. Twenty five patients died $<30$ days after surgery, 21 of cardiac failure. This high mortality reflects the type of patients included in the series. Only 12 received antiarrhythmic drugs after surgery. Perioperative mortality was related to preoperative left ventricular function and the context of surgery. Mortality rates for elective surgery more than eight weeks after infarction, early surgery, emergency surgery, and early emergency surgery were $18 \%, 31 \%, 46 \%$, and $50 \%$, respectively. Actuarial survival rates at one, three, five, and 10 years after surgery were $66 \%, 62 \%, 57 \%$, and $35 \%$.

Conclusions-Surgery offers arrhythmia abolition at a risk proportional to the patient's preoperative risk of death from ventricular arrhythmias. The long term follow up results suggest a continuing role for surgery in selected patients even in the era of catheter ablation and implantable defibrillators.

(Heart 1999;82:156-162)
\end{abstract}

Keywords: arrhythmias; myocardial infarction; surgical management

Surgical techniques to abolish ventricular tachycardia secondary to myocardial infarction were first described in patients in $1978 .{ }^{12}$ They developed as part of the growing recognition of the poor prognosis of patients with recurrent ventricular tachycardia and the inadequacies of medical treatment. ${ }^{34}$ Many cardiac surgery units developed antiarrhythmic surgical programmes and regularly performed antiarrhythmic operations over the next 10 years..$^{5-10}$ However, little consensus emerged on many of the fundamental issues involved. There were major differences between units in their referral patterns, their patient selection criteria, ${ }^{112}{ }^{12}$ the operative techniques used, ${ }^{13-18}$ and how they were guided. ${ }^{19-22}$

The advent of implantable defibrillators and their success in preventing arrhythmic deaths was accepted as providing the answer to the clinical problem - a readily deployable, lower risk, more understandable treatment. In contrast, the risks of antiarrhythmic surgery were seen as unacceptably high for most patients. Although there have been few attempts at randomised trials comparing antiarrhythmic surgery with either antiarrhythmic drugs or defibrillator treatment, the numbers of patients undergoing antiarrhythmic surgery has rapidly declined worldwide over the last 10 years. $^{23}$ Most commentators consider that surgical treatment for arrhythmias is now obsolete and will soon cease to be performed altogether. ${ }^{24}$

The commonest cause of ventricular tachycardia is remote myocardial infarction. This study had two aims. First, to define short and long term results of a series of patients undergoing map guided endocardial resection for postinfarction ventricular tachycardia at a time when this was the only non-pharmacological treatment deployed; and second, to relate surgical outcome to clinically recognisable patient subgroups.

\section{Methods}

Electrophysiologically guided endocardial resections have been performed at this hospital since March 1981. In the period March 1981 to August 1991, surgery was offered to all patients whose ventricular tachyarrhythmias could not be controlled by drug treatment, on the basis that their prognosis could be improved by surgery. No patient was refused surgery on the grounds of proximity to time of infarction, ${ }^{24}$ age, or arrhythmia type. ${ }^{19}$ Alternative treatments such as the automatic implantable cardioverter defibrillator and cardiac transplantation were not used in this type of patient at this hospital for all but the last year of this series. Even severe left ventricular dysfunc- 
tion, therefore, was not seen to be an absolute contraindication to surgery. Therefore this report represents outcome in a consecutive group of infarct survivors with drug refractory ventricular tachyarrhythmias treated at a time when antiarrhythmic surgery was the only non-pharmacological treatment deployed.

PREOPERATIVE MANAGEMENT

The antiarrhythmic drug treatments used before surgery reflected practice at the time of data collection. In many, however, arrhythmia episodes were too frequent to allow testing of multiple drugs, and early recourse to surgery was recommended to avoid further myocardial damage caused by multiple arrhythmic episodes and resuscitations. ${ }^{25}$

Coronary angiography was performed in all patients, and biplane left ventriculography in most. Significant coronary artery disease was defined by the presence of a $75 \%$ or greater stenosis in a major epicardial artery. Left ventricular ejection fraction was calculated from the $30^{\circ}$ right anterior oblique cineangiogram projection.

Preoperative programmed ventricular stimulation was performed routinely following angiography, except in patients who had experienced arrhythmia recurrences on their latest drug regimen. On the basis of their clinical management, patients were divided according to the context and timing of their antiarrhythmic operation. Thus, "emergency surgery" was arbitrarily defined as surgery unplanned within the previous 24 hours, and implied an operation performed in the context of frequently recurring or incessant arrhythmias. All other operations were "elective." Similarly, surgery undertaken within two months of the most recent infarction was deemed "early" and that performed more than two months after infarction as "late." There was, understandably, overlap between the early and emergency subgroups.

ANAESTHETIC POLICY

Premedication for surgery, anaesthetic induction methodology, and anaesthetic agents were not controlled. Bypass priming fluids also varied between patients but blood cardioplegia was not used.

\section{INTRAOPERATIVE MAPPING STRATEGY}

All patients had 53 point epicardial mapping performed in sinus rhythm while supported on normothermic cardiopulmonary bypass. In patients whose clinical arrhythmia included episodes of sustained monomorphic ventricular tachycardia, attempts were made to initiate the arrhythmia by programmed stimulation. If stable tachycardia was induced, epicardial activation mapping was performed to distinguish macro reentry from the more usual micro reentrant form of ventricular tachycardia. ${ }^{20} 2627$ Isoprenaline was not used to facilitate arrhythmia induction intraoperatively. After opening the left ventricle through the most abnormal segment to inspection, 36 point endocardial mapping was performed in sinus rhythm in all patients and, if inducible, an endocardial activation map was acquired in ventricular tachycardia. All mapping was performed using a hand held, bipolar electrode with a $1-1.5 \mathrm{~mm}$ interelectrode separation. All signals were filtered at $30-300 \mathrm{~Hz}$ and local electrograms consistently longer than $100 \mathrm{~ms}$ in sinus rhythm were designated abnormal ("fragmented"). ${ }^{19}$ Local activation was timed relative to the signal from a fixed reference electrode sited in normal ventricular myocardium. Before chest closure after rewarming the heart to $37^{\circ} \mathrm{C}$, programmed stimulation was repeated while the patient was still on cardiopulmonary bypass.

\section{SURGICAL STRATEGY}

Although focused on areas of earliest activation from the endocardial activation map of ventricular tachycardia, endocardial resections were based primarily on the results of fragmentation mapping in sinus rhythm with the aim of removing all electrically abnormal left ventricular endocardium. If sustained ventricular tachycardia could not be induced intraoperatively, resections were guided by the results of sinus rhythm mapping alone. This strategy amounted to removal of all visible endocardial scar in areas showing fractionated electrograms in sinus rhythm or over a wide margin centred on areas of earliest activation in ventricular tachycardia. However, endocardial scar was only resected in other areas if it also showed fractionated electrograms in sinus rhythm. Resections were performed on normothermic bypass, except in the case of arrhythmias arising in the inferobasal region. ${ }^{13}{ }^{1728}$ To improve visualisation in these, cardioplegia was applied before endocardial resections were performed. When sustained arrhythmias remained inducible despite initial resections, additional antiarrhythmic procedures such as more extensive endocardial resections, ventriculotomies, and cryoablations were deployed, guided by sequential activation mapping. ${ }^{16}$ Cryolesions were used to ablate deeper circuits in areas where endocardial resections had already been performed, where further resection threatened valve function or the integrity of the interventricular septum, or to unresectable areas such as papillary muscles or the mitral valve isthmus. ${ }^{13} 28$

Aneurysmectomy was undertaken for circumscribed areas of left ventricular scar with dyskinetic systolic motion identified by ventriculography and confirmed at surgery. The ventriculotomy was repaired using Teflon buttressed sutures rather than by patch closure. After ventricular repair, coronary grafting was performed where indicated.

FOLLOW UP AFTER DISCHARGE

Information regarding patients' progress after discharge was complete and was derived from outpatient attendances or from details provided by the patients' general practitioners. All patients discharged alive after surgery were registered with the Office of Population Censuses and Surveys (OPCS). This ensured that all late deaths were notified within three 
months and a copy of the death certificate provided to the hospital.

\section{STATISTICAL METHODS}

Unless otherwise stated, all values are expressed as mean (SD). Subgroup comparisons are made using the Student's unpaired $t$ test, and survival curve comparisons by log-rank testing. Probability (p) values of $<0.05$ on $\chi^{2}$ were considered significant.

\section{Results}

Figure 1 plots the number of patients undergoing map guided surgery for postinfarction arrhythmias in each year of the programme, identifying the cohort of 100 patients under study.

\section{PATIENT CHARACTERISTICS}

The mean (SD) age of the patients undergoing surgery was 56 (10) years; 81 were male and 19 female. The most recent infarction was anterior or lateral in 72 , inferior or posterior in 27 , and involved multiple sites in one. Twenty had experienced more than one infarct. Mean left ventricular ejection fraction was $28(10) \%$, left ventricular end diastolic pressure 20 (7) $\mathrm{mm}$ $\mathrm{Hg}$, and 60 patients had left ventricular aneurysms. Twenty eight patients had single vessel, 42 two vessel, and 30 triple vessel disease.

\section{ARRHYTHMIA CHARACTERISTICS}

Arrhythmias began a median of four weeks (range 48 hours to 10 years) after the last proven infarct. The initial presentation was with cardiac arrest or pulseless ventricular tachycardia in 41 patients and with tolerated ventricular tachycardia in 59. All had episodes of sustained monomorphic ventricular tachycardia, but in 44 some episodes degenerated to ventricular fibrillation. Mean number of major episodes of arrhythmia was 11 per patient
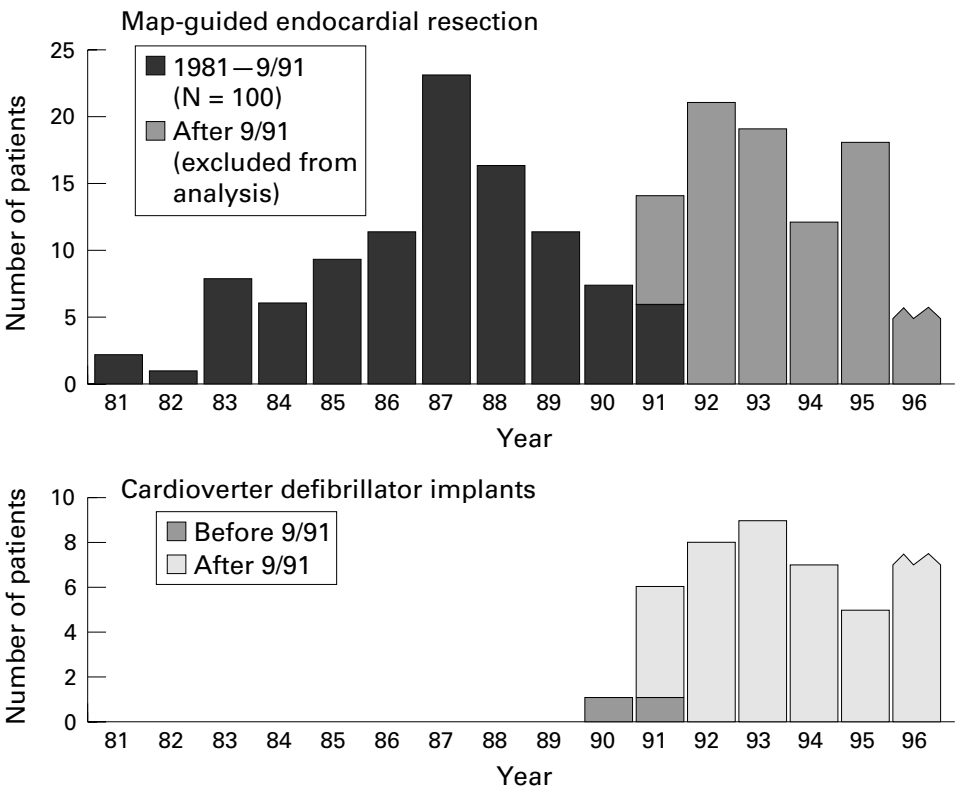

Figure 1 Number of patients operated on each year in the series of 100 patients. Series ended with change in surgical selection criteria made possible by advent of implantable defibrillators.
Table 1 Extent of surgery performed in 100 patients

\begin{tabular}{lc}
\hline Procedure & $n$ \\
\hline Endocardial resections (left ventricle) & 100 \\
Additional antiarrhythmic procedures & 26 \\
Cryoablations & 12 \\
Ventriculotomies & 4 \\
Endocardial resection (right ventricle) & 71 \\
Additional procedures & 57 \\
Coronary bypass grafting & 7 \\
Aneurysmectomy/infarctectomy & 2 \\
Mitral valve replacement & \\
Ventricular septal defect repair & \\
\hline
\end{tabular}

${ }^{\star}$ Mean grafts/patient grafted $=2.4 ;$ median total bypass time 157 minutes.

(range 2 to 200), and the majority of these required electrical cardioversion. Three patients were in incessant tachycardia at the time of surgery. Mean tachycardia cycle length of the fastest documented sustained monomorphic arrhythmia was 322 (64) ms. Patients had failed a mean of 4 (2) antiarrhythmic drugs before surgery. Amiodarone, lignocaine (lidocaine), and flecainide had failed in the majority of patients. In the 28 patients who underwent emergency surgery, arrhythmic episodes were too frequent to allow testing of multiple drugs.

INDICATIONS AND CONTEXT OF SURGERY

Control of arrhythmias was the only indication for surgery in 80 patients. The remaining 20 had additional indications for surgery: angina pectoris in 13, aneurysmectomy for cardiac failure in three, mitral valve replacement for regurgitation in three, and repair of a ventricular septal defect in one. Mean time from infarction to surgery was 25 months. However, six required surgery within two weeks of infarction, 15 within one month, 32 within two months, and 37 within three months. Emergency surgery was undertaken in 28 .

All 100 patients underwent map guided endocardial resections in the left ventricle. Table 1 summarises the extent of surgery in the group. Median total bypass time was 157 minutes (range 61 to 449 ) and mean number of grafts sited per patient revascularised was 2.4. Intraoperatively, sustained ventricular tachycardia was induced in 71 patients. Complete epicardial and endocardial activation mapping in ventricular tachycardia was obtained in 43 patients, epicardial alone in 26 , and endocardial alone in two. In 29 patients, surgery was guided only by sinus rhythm mapping.

EARLY POSTOPERATIVE OUTCOME

Twenty five patients died within 30 days of surgery, 21 of low output cardiac failure. Twenty had intra-aortic balloon pumps and two had left ventricular assist devices inserted perioperatively. One patient survived only by having a heart transplant 48 hours after arrhythmia surgery. Deaths from heart failure in this period were related to the patients' Killip class of heart failure just before surgery (class I $v$ class II, $\mathrm{p}=0.05$; class $\mathrm{I} v$ class III/IV, $\mathrm{p}=0.01$ ) and to the angiogram derived left ventricular wall motion score (wall motion score $<3 v>3 ; \mathrm{p}=0.04$ ). However, death was not related to preoperative ejection fraction or other measures of ventricular function. ${ }^{12}$ Of the 
Table 230 Day mortality by context and timing of surgery

\begin{tabular}{|c|c|c|c|c|}
\hline & $n$ & $\begin{array}{l}\text { Deaths } \leqslant 30 \\
\text { days }\end{array}$ & Mortality (\%) & p Value \\
\hline Total group & 100 & 25 & 25 & \\
\hline \multicolumn{5}{|l|}{ Context } \\
\hline Emergency surgery & 28 & 11 & 39 & $<0.003$ \\
\hline Elective surgery & 72 & 12 & 17 & \\
\hline \multicolumn{5}{|l|}{ Timing from MI } \\
\hline$<2$ weeks & 6 & 3 & $50^{\star}$ & 0.001 \\
\hline$\leqslant 1$ month & 9 & 3 & 33 & 0.09 \\
\hline$\leqslant 2$ months & 32 & 10 & 31 & 0.13 \\
\hline$>2$ months & 68 & 14 & 21 & \\
\hline \multicolumn{5}{|l|}{ Context and timing from $\mathrm{MI}$} \\
\hline Elective operation; $>2$ months & 56 & 10 & 18 & \\
\hline Emergency operation; $>2$ months & 12 & 4 & 33 & \\
\hline Emergency operation $; \leqslant 2$ months & 16 & 8 & 50 & \\
\hline Emergency operation; $\leqslant 1$ month & 10 & 5 & 50 & \\
\hline
\end{tabular}

$\star<2$ weeks $v \geqslant 2$ weeks.

MI, myocardial infarction.

remaining four deaths, two were caused by irreversible brain injury and two occurred suddenly, one in the context of profound bradycardia and the other during unmonitored sleep, presumed from a ventricular tachyarrhythmia.

Outcome within 30 days of surgery was also related to the context of surgery and to its timing after infarction (table 2). Of 72 patients who underwent elective surgery, $12(17 \%)$ died, compared with 13 of 28 (46\%) who required emergency surgery $(\mathrm{p}<0.003)$. Three of the six patients having surgery within two weeks of infarction died, compared with three of nine operated upon between two weeks and one month, and four of 17 operated upon between one and two months. There was a significantly increased mortality in patients undergoing surgery within two weeks of infarction compared with later times $(\mathrm{p}<0.001)$.

Thirty day mortality was $32 \%$ (13 of 41 ) in those whose initial presentation was with cardiac arrest or pulseless ventricular tachycardia, and $22 \%$ (12 of 59) in those with well tolerated tachycardia $(\mathrm{p}=0.19)$.

Median hospital stay after surgery was 12.5 days for the whole group and 15 days (range 7 to 37 ) for those discharged alive.

LONG TERM FOLLOW UP

Of the 75 who survived the first 30 days after surgery, 35 died during median follow up of 5.6 years (range 5.25 to 13.25 years). Figure 2 plots actuarial survival for the study group and, for comparison, actuarial curves for series of

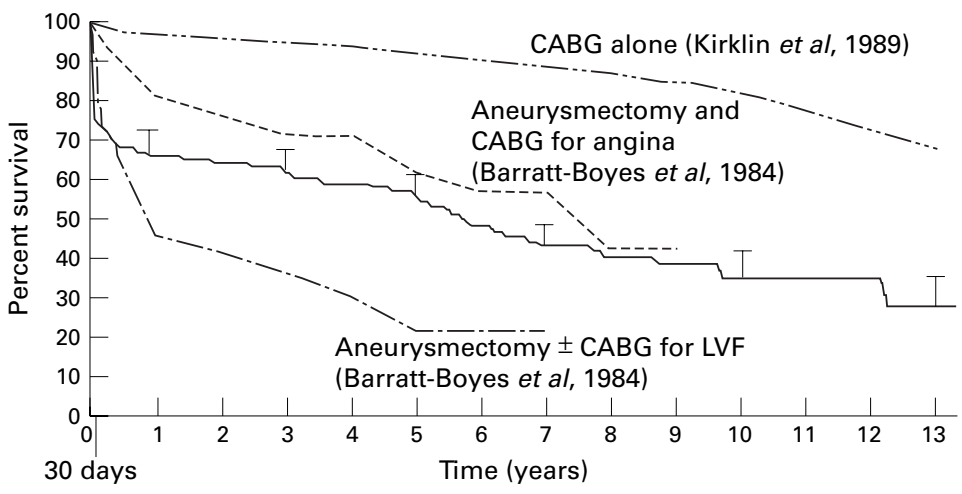

Figure 2 Actuarial survival for the study group and, for comparison, actuarial curves for cohorts of patients from published reports undergoing coronary revascularisation alone, ${ }^{29}$ and aneurysmectomy for angina or for heart failure. ${ }^{30} \mathrm{CABG}$, coronary artery bypass graft; LVF, left ventricular failure. patients from published reports who had coronary revascularisation alone, ${ }^{29}$ and aneurysmectomy for angina or for heart failure. ${ }^{30}$ Twenty five $(71 \%)$ of the late deaths were from cardiac causes and 10 (29\%) from non-cardiac causes. Causes and follow up duration of the late cardiac deaths were mediastinitis in one (three months), ventricular fibrillation after cholecystectomy in one (four months), heart failure without reinfarction in 11 (51 (44) months), heart failure following reinfarction in 12 (59 (33) months). Causes of the noncardiac deaths were malignancy (6), pneumonia (2), stroke (1), and abdominal aortic disease (1), occurring at a mean of 52 (31) months.

\section{ANTIARRHYTHMIC OUTCOME OF SURGERY}

The occurrence of sustained monomorphic ventricular tachycardia within two years, regardless of morphology or cycle length, was taken as antiarrhythmic failure of surgery. By these criteria, surgery failed in 13 patients. These arrhythmic events occurred in 10 before and in three after initial hospital discharge. In one of the 10, arrhythmias occurred while the patient was on high dose inotropic and mechanical support, before death from cardiac failure. Eight of the remaining nine were discharged on drug treatment (amiodarone in six, flecainide in one, mexiletine in one) and one on no treatment. None experienced further arrhythmias during prolonged follow up.

Arrhythmias recurred for the first time between two and four months after hospital discharge in the remaining three patients. One died despite restoration of sinus rhythm, and two presented in well tolerated ventricular tachycardia. These two remained arrhythmia free during prolonged follow up on antiarrhythmic treatment which had been ineffective before surgery. Thus antiarrhythmic drug treatment combined with the effects of "failed" surgery prevented further recurrences in 10 of 13 patients and one required no maintenance antiarrhythmic drug treatment.

INFLUENCE OF ARRHYTHMIA ORIGIN ON

RECURRENCE RATE AFTER SURGERY

Of the 13 patients with spontaneous arrhythmia recurrences after surgery, five had anterior or septal and eight inferior or posterior arrhythmia generators. Arrhythmia recurrence rates were related significantly to their site of origin, with only $7 \%$ (five of 73 ) with anterior generators recurring compared with 30\% (eight of 27) with inferior generators $(\mathrm{p}=0.003)$.

\section{Discussion}

In the absence of randomised studies comparing surgery with other methods of treatment in similar types of patients with postinfarction ventricular tachyarrhythmias, these results provide a basis for comparison with those of other treatments- that is, continued drug treatment, catheter ablation, and implantable defibrillators. Numerous series of patients with ventricular tachycardia treated surgically have already been reported ${ }^{5-11} 14-1621$ 34-36 $^{40}$; however, 
the value of this series lies in the fact that it reports results derived from a series of consecutive patients with postinfarction ventricular tachycardia who underwent surgery in a uniform way at a single hospital, at a time when patient selection was not influenced by the availability of other non-pharmacological treatments. Therefore, uniquely, our results report the outcome of surgery when applied non-selectively by then current criteria. Perhaps more importantly, the results include long term follow up of all patients, providing insight into the causes of late deaths in this type of patient.

EARLY POSTOPERATIVE OUTCOME

The overall 30 day mortality of $25 \%$ for the series is high, supporting the view that antiarrhythmic surgery needs to be used selectively now that alternatives exist. However, the heterogeneity of the population of patients with postinfarction ventricular tachyarrhythmias and their differing prognoses is also evident. The high overall mortality is explained in part by the inclusion of a subgroup of 28 who required emergency surgery and by the fact that 32 underwent surgery within two months of infarction.

Even had implantable defibrillator treatment been available at the time, neither the emergency group nor many of those undergoing planned surgery within weeks of infarction would have been suitable for it, because of the frequency of their arrhythmias. ${ }^{31}$ The 50\% mortality rate observed in the subgroup of 16 patients who underwent emergency antiarrhythmic operations within two months of infarction should not be interpreted as a misuse of surgery, but rather as saving $50 \%$ of a group whose anticipated mortality would have approached $100 \%$ without it. ${ }^{19}$ The decision making process for surgery in this type of patient is similar to that in patients without arrhythmias but with postinfarction ventricular septal defects or papillary muscle rupture, where the timing of the operation is critical and the outcome uncertain. Paradoxically, the availability of implantable defibrillators may result in an even higher proportion of a reduced surgical population in the future being comprised of patients with intractable arrhythmias in the early postinfarction period, for whom no treatment is truly ideal.

The 30 day mortality rate of $18 \%$ in the elective surgical group operated upon more than two months after infarction is, however, unacceptably high by present standards. This figure reflects the non-selective use of surgery, forced by the lack of alternative treatments at the time of data collection. The initial clinical presentation with cardiac arrest or pulseless ventricular tachycardia in 41 of the patients, however, confirms their high risk of arrhythmic death and the appropriateness, therefore, of non-pharmacological treatment. ${ }^{32}$ Now that both surgery and device treatments are readily available, the outlook for patients in this category has improved substantially. ${ }^{33-35}$ The selective use of surgery in ideal surgical candidates, who have sustained anterior infarct but have preserved left ventricular function in other segments and no important comorbidity, allows surgery with a $1-5 \%$ risk. ${ }^{35-37}$ Device treatment provides protection from arrhythmic death in the remainder at negligible implant risk. $^{38}$

The results of this series also show that a patient's risk of dying within 30 days of surgery from cardiac failure could be identified from their preoperative left ventricular wall motion score, their Killip class of heart failure, and the context and timing of their operation. Thus mortality ranged from $50 \%$ in patients who underwent emergency surgery within two months of acute infarction to $18 \%$ in those undergoing elective operations more than two months after infarction.

\section{LONGER TERM OUTCOME AFTER}

ANTIARRHYTHMIC SURGERY

Surgical treatment offers not just arrhythmia abolition but also an opportunity for complete revascularisation and ventricular remodelling by aneurysmectomy or infarctectomy as clinically indicated. This series, with mean follow up of 6.7 years in the 75 patients who survived the early postoperative period, provides new insights into the causes of late deaths following antiarrhythmic surgery. Competing causes for death in this time period included heart failure, malignancy, and non-cardiac vascular disease. The prolonged mean survivals before death from cardiac failure without reinfarction, from heart failure following reinfarction, and from non-cardiac causes of 51 (44), 59 (33), and 52 (31) months, respectively, supports the view that revascularisation with or without aneurysmectomy contributed additional benefits to the antiarrhythmic outcome of the operation. The fact that $29 \%$ of all late deaths had a non-cardiac cause could be interpreted as suggesting that surgery changed the natural history of the cardiac disease. Further support for this view is provided by comparison of actuarial survival in patients who underwent emergency versus elective surgery. Although 30 day mortality was significantly higher in those undergoing emergency operations, their longer term course was not one of progressive decline but of long term, event free survival comparable with that seen in those undergoing elective surgery.

\section{ARRHYTHMIA ABOLITION BY ANTIARRHYTHMIC} SURGERY

The criteria used to define arrhythmia recurrences after surgery in this study were intentionally rigorous. However, surgery abolished arrhythmias completely in $87 \%$ of the group and failed to achieve this primary goal in 13 $(13 \%)$. Recurrences in these 13 caused or at least contributed to the deaths of two. However, the fact that none of the other 11 who survived their initial recurrences experienced further spontaneous episodes after restarting previously ineffective antiarrhythmic drug treatment suggests that surgery was at least partly successful even in these surgical failures. If both partial and complete successes are considered as beneficial, the antiarrhythmic suc- 
cess rate for the series rises to $98 \%$ in survivors. The ability of map guided endocardial resection to abolish arrhythmias in patients with postinfarction ventricular tachycardia is therefore not in doubt.

\section{SITE OF ARRHYTHMIA ORIGIN AND}

ANTIARRHYTHMIC OUTCOME OF SURGERY

Arrhythmia recurrences after surgery were significantly related to their site of origin. Patients whose arrhythmias mapped to the inferobasal or posterobasal regions of the left ventricle had a 30\% recurrence rate as compared with the $7 \%$ rate for those arising elsewhere. This finding is consistent with the results from other series and relates primarily to the difficulties of surgical access to these regions. ${ }^{11} 12173940$ The consistently lower arrhythmia abolition rate reported from this and most surgical series in patients with arrhythmias arising inferobasally makes it more difficult to recommend antiarrhythmic surgery to patients who do not also require surgical revascularisation or aneurysmectomy.

\section{CONCLUSIONS}

The results of this series confirm the antiarrhythmic success of map guided endocardial resection in patients with postinfarction ventricular tachyarrhythmias. Mortality rates in the early postoperative period are related to left ventricular wall motion score before surgery and crudely to the patient's risk of arrhythmic death without surgery, based on variables reflecting the context and timing of the operation. For patients with infrequent life threatening arrhythmias, who are also suitable for defibrillator treatment, surgery is best reserved for "ideal" surgical candidates. These include younger patients without important comorbidity who have large anteroapical aneurysms but preserved left ventricular function in other regions and who have a single clinical morphology of ventricular tachycardia which is haemodynamically compromising. If preoperative mapping confirms that the arrhythmia does not originate in the basal septum, high arrhythmia cure rates can be achieved with a $1-5 \% 30$ day mortality risk. Other categories of patient should not be precluded automatically, however. Emergency surgery has a particular role in patients who are not in overt cardiac failure but who have frequent cardiac arrests within weeks of acute infarction.

We acknowledge particularly the contribution of the following members of the cardiology, cardiac surgical, and technical support teams at Freeman Hospital who contributed significantly at various times to the antiarrhythmic surgical progran F Guzman, A Renzulli, S Khan, B Glenville, J Forty, D S Reid, P Kertes, J C Cowan, S Tansuphaswadikul, C Griffiths, A Murray, $S$ Farr, and V Price. The university department of cardiology is supported by the British Heart Foundation.

1 Guiraudon G, Fontaine G, Frank R, et al. Encircling endocardial ventriculotomy: a new surgical treatment for life-threatening ventricular tachycardia resistant to medical treatment following myocardial infarction. Ann Thorac Surg 1978;26:438-44

2 Josephson ME, Harken AH, Horowitz LN. Endocardial excision: a new surgical technique for the treatment of recurrent ventricular tachycardia. Circulation 1979;60: $1430-9$.

3 Willems AR, Tijssen JGP, van Capelle FJL, et al. Determinants of prognosis in symptomatic ventricular Determinants of prognosis in symptomatic ventricular
tachycardia or ventricular fibrillation late after myocardial infarction. f Am Coll Cardiol 1990;16:521-30. 4 Teo KK, Yusuf S, Furberg CD. Effects of prophylactic
antiarrhythmic drug therapy in acute myocardial infarcantiarrhythmic drug therapy in acute myocardial infarction. An overview of results from
trials. FAMA 1993;270:1589-95.

5 Josephson ME, Harken AH, Horowitz LN. Long-term results of endocardial resection for sustained VT in coronary disease patients. Am Heart f 1982;104:51-7.

6 Brodman R, Fisher JD, Johston DR, et al. Results of electrophysiologically guided operations for drug-resistant recurrent ventricular tachycardia and ventricular fibrillation due to coronary artery disease. F Thorac Cardiovasc Surg 1984; $87: 431-8$

7 Garan H, Nguyen K, McGovern B, et al. Perioperative and long-term results after electrophysiologically directed ventricular surgery for recurrent ventricular tachycardia. $7 \mathrm{Am}$ Coll Cardiol 1986;8:201-9.

8 Martinelli L, Coggi C, Graffigna A, et al. The role of surgery in the treatment of postinfarction ventricular tachycardia. A 5 year experience. 7 Thorac Cardiovasc Surg 1987;28: 374-9.

9 Borggrefe M, Podczeck A, Ostermeyer J, et al. Long-term results of electrophysiologically guided antitachycardia surgery in ventricular tachyarrhythmias. A collaborative study on 665 patients. In: Breithardt G, Borggrefe M, Zipes DP, eds. Non-pharmacological therapy of tachy-arrhythmias. New York: Futura, 1987:109-32.

10 Ostermeyer J, Kirklin JK, Borggrefe $M$, et al. Ten years electro-physiologically guided direct operations for malignant ischaemic ventricular tachycardia-results. f Thorac Cardiovasc Surg 1989;37:20-7.

11 Cox JL. Patient selection criteria and results of surgery for refractory ischaemic ventricular tachycardia. Circulation 1989;79(suppl 1):I-163-77.

12 Bourke JP, Gray J, Hilton CJ, et al. Predictors of death from cardiac failure within 30 days of map guided endocardial resection for post-infarction ventricular tachycardia. Ann Thorac Surg. [In press.]

13 Ott DA, Garson A, Cooley DA, et al. Cryoablative techniques in the treatment of cardiac tachyarrhythmias. Ann Thorac Surg 1987;43:138-43.

14 Bolooki HM, Palatianos GM, Zaman L, et al. Surgical management of post-myocardial infarction ventricular tachyarrhythmia by myocardial debulking, septal isolation and myocardial revascularization. I Thorac Cardiovasc Surg 1986;92:716-25.

15 Krafchek J, Lawrie GM, Roberts R, et al. Surgical ablation of ventricular tachycardia: Improved results with map-
directed regional approach. Circulation 1986;73:1239-47.

16 Kron IL, Lerman BB, Nolan SP, et al. Sequential endocardial resection for the surgical treatment of refractory ventricular tachycardia. F Thorac Cardiovasc Surg 1987;94:843-7.

17 Hargrove WC, Miller JM, Vassallo JA, et al. Improved results in the operative management of ventricular tachycardia in the operative management of ventricular tachycardia isthmus. F Thorac Cardiovasc Surg 1986;92:726-32.

18 Svenson RH, Gallagher JJ, Selle JG, et al. Neodymium: YAG laser photocoagulation: a successful new map-guided technique for the intraoperative ablation of ventricular tachycardia. Circulation 1987;76:1319-28.

19 Bourke JP, Campbell RWF, Renzulli A, et al. Surgery for ventricular tachyarrhythmia based on fragmentation mapping in sinus rhythm alone. Eur f Cardiothorac Surg 1989;3: $401-7$.

20 Gallagher JJ, Kasell JH, Cox JL, et al. Techniques of intraoperative electrophysiologic mapping. Am $\mathcal{F}$ Cardiol 1982;49:221-40.

21 Landymore RW, Kinley CE, Gardner M, et al. Encircling endocardial resection with complete removal of endocardial scar without intraoperative mapping for the ablation of drug-resistant ventricular tachycardia. $尹$ Thorac Cardiovasc Surg 1985;89:18-24.

22 Downar E, Masse S, Chen TCK, et al. An approach to three-dimensional mapping of clinical ventricular arrhythmias. In: Shenasa M, Broggrefe M, Breithardt G, eds. Cardiac mapping. New York: Futura Publishing, 1993:515-22.

23 van Hemel NM, Kingma JH, Defauw JJ, et al. Continuation of antiarrhythmic drugs, or arrhythmia surgery after multiple drug failures. A randomized trial in the treatment of postinfarction ventricular tachycardia. Eur Heart f 1996; 17:564-73.

24 Bourke JP, Hilton CJ, McComb JM, et al. Surgery for control of recurrent life-threatening ventricular tachyarrhyth-
mias within two months of myocardial infarction. $\mathscr{f} \mathrm{Am} \mathrm{Coll}$ Cardiol 1990;16:42-8.

25 Runsio M, Bergfeldt L, Brodin LA, et al. Left ventricular function after repeated episodes of ventricular fibrillations function after repeated episodes of ventricular fibrillations cardiography. Eur Heart $\mathcal{F}$ 1997;18:124-31.

26 Lehmann ML, Denker S, Mahmud R, et al. Linking: a dynamic electrophysiologic phenomenon in macroreentry circuits. Circulation 1985;71:254-65.

27 Waspe LE, Brodman R, Kim SG, et al. Activation mapping in patients with coronary artery disease with multiple ventricular tachycardia configurations: occurrence and therapeutic implications of widely separate apparent sites of origin. F Am Coll Cardiol 1985;5:1075-86.

28 Kron IL, Di Marco JP, Lerman BB, et al. Resection of scarred papillary muscles improves outcome after surgery for ventricular tachycardia. Ann Surg 1986;203:685-90.

29 Kirklin JK, Naftel DC, Blackstone EH, et al. Risk factors for mortality after primary valvular and coronary artery mortality after primary valvular and coron
surgery. Circulation 1989;79(suppl I):I-185-90.

30 Barratt Boyes BG, White HD, Agnew TM, et al. The results of surgical treatment of left ventricular aneurysms: an 
assessment of the risk factors affecting early and late mortality. F Thorac Cardiovasc Surg 1984;87:87-98.

31 Brethardt G, Camm AJ, Campbell RWF, et al. Task Force of the Working Groups on Cardiac Arrhythmias and Cardiac Pacing of the European Society of Cardiology. Guidelines for the use of implantable cardioverter defibrillators. Eur Heart f 1992;13:1304-10.

32 Brugada P, Talajic M, Smeets J, et al. The value of the clinical history to assess prognosis of patients with ventricular tachycardia or ventricular fibrillation after myocardia infarction. Eur Heart 7 1989;10:747-52.

33 Choue CW, Kim SG, Fisher JD, et al. Comparison of defibrillator therapy and other therapeutic modalities of sustained ventricular tachycardia on ventricular fibrillation associated with coronary artery disease. Am $\mathcal{f}$ Cardiol 1994; 73:1075-9.

34 Trappe HJ, Klein H, Wenzlaff $\mathrm{P}$, et al. Ventricular tachycardia surgery in 1992: did the automatic defibrillator change dia surgery in 1992: did the automatic
this approach? PACE 1993;16:242-6.

35 van Hemel NM, Kingma JH, Defauw JJ, et al. Left ventricular segmental wall motion score as a criterion for selecting patients for direct surgery in the treatment of postinfarction ventricular tachycardia. Eur Heart $\mathcal{F}$ 1989;10:304-15.

36 Lee R, Mitchell JD, Garan H, et al. Operation for recurrent ventricular tachycardia: predictors of short-term and longterm efficacy. F Thorac Cardiovasc Surg 1994;107:732-42.

37 Selle JG, Svenson RH, Gallagher JJ, et al. Surgical-treatment of ventricular-tachycardia with Nd-Yag laser photocoagulation. PACE 1992;15:1357-61.

38 The PCD Investigation Group. Clinical outcome of patients with malignant ventricular tachyarrhythmias and multiprogrammable implantable cardioverter defibrillator implanted with or without thoracotomy. An internation multi-centre study. F Am Coll Cardiol 1994;23:1521-30.

39 Miller JM, Kienzle MG, Harken AH, et al. Subendocardial resection for ventricular tachycardia: predictors of surgical success. Circulation 1984;70:624-31.

40 Lawrie GM, Pacifico A, Kaushik R, et al. Factors predictive of results of direct ablative operations for drug-refractory ventricular tachycardia: analysis of 80 patients. I Thorac Cardiovasc Surg 1991;101:44-55. 